\title{
Inventário Arbóreo das vias públicas do Centro de João Pessoa, Paraíba
}

Os problemas criados pelo processo de urbanização estão fazendo as cidades prestarem maior atenção à sua arborização. João Pessoa (PB) é uma cidade que conta com inúmeras áreas verdes, tendo sua arborização central se estabelecido desde 1950. A manutenção da arborização urbana requer o seu diagnóstico e um constante monitoramento, no sentido de garantir a beleza e a saúde das árvores, bem como o usufruto dos seus benefícios ecológicos. Com isso, objetivou-se identificar as espécies arbóreas em 12 vias centrais mais arborizadas de João Pessoa, e também analisar os parâmetros altura, DAP e altura da primeira ramificação. A pesquisa foi realizada de dezembro/2009 a agosto/2010, registrando um total de 527 indivíduos, distribuídos em 32 espécies e 12 famílias. As 11 espécies mais frequentes corresponderam a $91 \%$ do total, sendo $81 \%$ exóticas. As mais abundantes foram Mangifera indica L. (24\%) e Eugenia malaccensis L. (13\%). As famílias mais frequentes foram Fabaceae (27,38\%), Anacardiaceae (25,05\%) e Bignoniaceae (16,7\%). A avenida com maior quantidade de árvores apresentou 62 indivíduos, enquanto o menor registro foi de 7. Com relação à diversidade, o número máximo de espécies encontrado por avenida foi 11 . Das árvores analisadas, $39 \%$ eram de grande porte, $35 \%$ apresentavam a primeira ramificação acima de $1,80 \mathrm{~m}$ e $55 \%$ possuíam o DAP inferior a $0,5 \mathrm{~m}$. Concluiu-se que a cidade apresenta poucas árvores ao longo de suas vias centrais e a maioria apresenta características que comprometem o fluxo, indicando a necessidade de um melhor planejamento da urbanização.

Palavras-chave: Inventário Arbóreo; João Pessoa; Arborização Urbana.

\section{Arboreal Inventory of the João Pessoa Center, Paraíba}

The problems created by the urbanization process are making many cities to pay more attention to their arborization. João Pessoa, despite of being a very old city has many green areas, having its urban trees established during 1950. The maintenance of urban afforestation requires its diagnosis and constant monitoring in order to guarantee the beauty and health of the trees, as well as the enjoyment of its ecological benefits. The aim of the study was to identify the arborization of the 12 main public streets of downtown João Pessoa, PB. The research was carried out from December / 2009 to August/2010, registering a total of 527 individuals, distributed in 32 species and 12 families. The 11 most frequent species correspond to $91 \%$ of the total population and $81 \%$ of them are exotic. The most abundant species were Mangifera indica L. (24\%) e Eugenia malaccensis L. (13\%). The most frequent families were Fabaceae (27. 38\%), Anacardiaceae (25.05\%) and Bignoniaceae (16.7\%). The avenue with the highest number of trees presented 62 individuals, while the lowest one was 7 . Regarding diversity, the maximum number of species found per avenue was 11 . About $39 \%$ of the trees were considered as big size. $35 \%$ of them had the first ramification above $1.80 \mathrm{~m}$. $55 \%$ have the DAP under $0.5 \mathrm{~m}$. It was concluded that the city has few trees along its central roads and most of them have characteristics that compromise the flow, indicating the need for a better urbanization planning.

Keywords: Arboreal Inventory; João Pessoa; Urban afforestation.

Topic: Planejamento Urbano

Reviewed anonymously in the process of blind peer.
Received: 02/12/2018

Approved: 26/01/2019
Sofia Erika Moreira Gomes

Universidade Federal da Paraíba, Brasil

http://lattes.cnpq.br/8505539177135230

sofiaerika@gmail.com

Maria Regina de Vasconcellos Barbosa (id

Universidade Federal da Paraíba, Brasil

http://lattes.cnpq.br/7317817178235471

http://orcid.org/0000-0001-6166-3922

mregina@dse.ufpb.br

Zelma Glebya Maciel Quirino (DD

Universidade Federal da Paraíba, Brasil

http://lattes.cnpq.br/2654243440511579

http://orcid.org/0000-0003-0396-107X

zelmaglebya@gmail.com

\section{Referencing this:}

GOMES, S. E. M.; BARBOSA, M. R. V.; QUIRINO, Z. G. M.. Inventário Arbóreo das vias públicas do Centro de João Pessoa, Paraíba. Revista Ibero Americana de Ciências Ambientais, v.10, n.1, p.351-362, 2019. DOI: http://doi.org/10.6008/CBPC2179-6858.2019.001.0029 


\section{INTRODUÇÃO}

As constantes preocupações com a degradação do meio ambiente e o processo de urbanização desordenado têm levado muitas cidades a destinarem uma maior atenção à sua arborização. A escassez de cobertura vegetal é um dos fatores mais relevantes para o aumento da temperatura superficial e o desconforto térmico da população (OLIVEIRA et al., 2017), tendo especial atenção atualmente frente às mudanças climáticas.

João Pessoa, apesar de ser uma cidade fundada em 1585, sendo portanto, uma das mais antigas do país, ainda conta com inúmeras áreas verdes, presentes tanto nos remanescentes de Mata Atlântica, quanto em sua arborização urbana. Entretanto, a capital paraibana sofre atualmente um crescente processo de verticalização e de expansão urbana, o que the têm causado diversos problemas ambientais tais como a destruição de áreas verdes (SILVA et al., 2015), com grandes impactos no nível de conforto térmico dos seus habitantes (SANTOS et al., 2012).

A cidade não dispõe de um sistema de fiscalização efetiva em suas áreas de preservação, sendo constantes as invasões por pessoas em busca de uma fonte de renda, através da coleta de produtos da mata e/ou da instalação de comércios clandestinos, ou para o despejo de lixo e esgoto. Além disso, tais áreas estão submetidas a inúmeras restrições legais, não estando facilmente disponíveis para que a população delas usufrua como áreas de lazer contemplativo e recreativo.

As áreas verdes de João Pessoa são constituídas por parques urbanos, mais de 180 praças e aproximadamente $27 \mathrm{~km}$ de vias arborizadas, das quais grande parte está concentrada em avenidas do centro. De acordo com Santos et al. (2012), a vegetação presente nestas áreas urbanas contribui para a amenização climática e serve como um regulador térmico, condicionando um melhor índice de conforto térmico, verificado na região central. A arborização destas avenidas centrais, definida até meados deste século, seguiu o propósito de estabelecer uma integração entre as praças e parques do centro da cidade, formando grandes corredores verdes que exercem funções ecológicas e estéticas (ANDRADE et al., 2015). A representação das principais vias do centro define uma boa amostra do perfil da arborização da cidade como um todo. Esses espaços públicos - as praças, parques urbanos e vias arborizadas - já se incorporaram de tal forma à vida da cidade que sua proteção e manutenção são garantidas por lei, pois compõem o patrimônio cultural do Estado, conforme rezam a Constituição do Estado da Paraíba (JOÃO PESSOA, 2013) e o Plano Diretor da Cidade de João Pessoa (JOÃO PESSOA, 1994).

Apesar de legalmente protegidas, as áreas verdes públicas estabelecidas ao longo da história de João Pessoa não se encontram em condições suficientemente adequadas. São visiveis os casos de remoção de indivíduos arbóreos por problemas como o apodrecimento dos caules provocado por pragas, indivíduos mutilados em virtude das interferências com os equipamentos urbanos e as alterações provocadas pelos cidadãos, que interferem tanto introduzindo indivíduos não adaptados ao ambiente público, como através procedimentos inadequados que acabam comprometendo a saúde das árvores, o que caracteriza a ausência de planejamento adequado para a manutenção. 
Este trabalho teve como objetivo quantificar e identificar as espécies arbóreas utilizadas na arborização das principais vias públicas do centro de João Pessoa, bem como analisar parâmetros básicos como altura, DAP e altura da primeira ramificação, no intuito de fornecer subsídios para a implantação de um efetivo planejamento da sua arborização urbana.

\section{MATERIAIS E MÉTODOS}

\section{Caracterização da área}

O Município de João Pessoa está localizado no extremo Leste do Estado da Paraíba, entre as

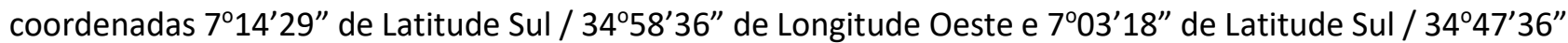
de Longitude Oeste, possuindo uma área total de $210,45 \mathrm{~km}^{2}$ (0,3\% da superfície do Estado) e altitude média em relação ao nível do mar de 37m (JOÃO PESSOA, 2012).

Segundo a classificação de Köeppen, o clima da cidade é do tipo As' - tropical quente e úmido com chuvas de outono e inverno com período de estiagem de 5 a 6 meses, a temperatura média é de $26^{\circ} \mathrm{C}$, tendo oscilações de $22^{\circ} \mathrm{C}$ a $30^{\circ} \mathrm{C}$ (IBGE, 2010). A cidade possui duas estações climáticas, o período chuvoso e o período seco. As chuvas mais intensas ocorrem no período de outono e inverno (de março a agosto). A pluviosidade alcança até $1700 \mathrm{~mm}$ anuais (AESA, 2011). O município está inserido no domínio da Mata Atlântica em um tipo florestal denominado Mata dos Tabuleiros.

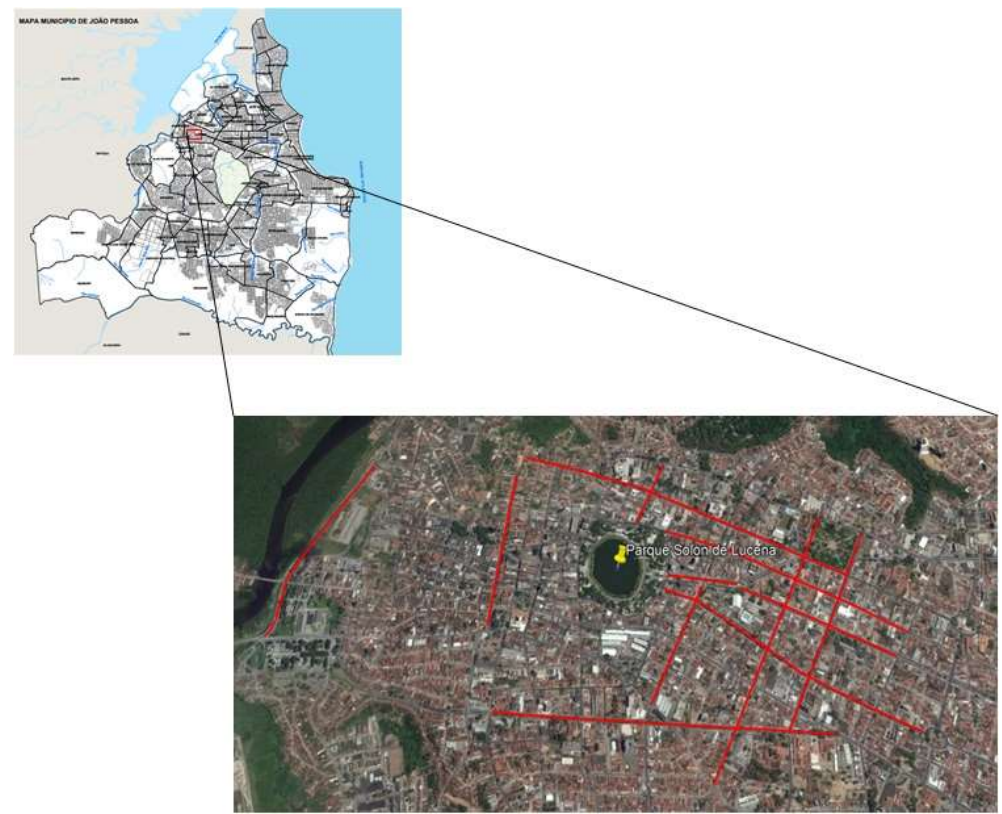

Figura 1: Localização das avenidas analisadas - Centro de João Pessoa/PB. Em destaque, as avenidas analisadas.

De acordo com o último censo do IBGE (2010), a população de João Pessoa era de 723.515 habitantes e a densidade demográfica é de $3.421,28 \mathrm{hab} . / \mathrm{km}^{2}$. Apresenta uma área bruta de $160,76 \mathrm{~km}^{2}$ e possui atualmente 64 bairros, com 78,4\% dos domicílios urbanos construídos em vias públicas com arborização e 25,1\% encontram-se em vias públicas com urbanização adequada.

Para o presente estudo foram escolhidas as principais vias públicas arborizadas do centro da cidade: Av. Almirante Barroso, Av. Pedro I, Av. Maximiano de Figueiredo, Av. João Machado, Av. Getúlio Vargas, Av. 
General Osório, Av. Camilo de Holanda, Av. Duarte da Silveira, Av. dos Tabajaras, Av. Coremas, Av. Sanhauá e a Rua Desembargador Souto Maior, totalizando 9,34 km. Estas avenidas compreendem áreas comerciais, residenciais e hospitalares (Figura 1).

\section{Coleta e análise dos dados}

O inventário utilizado no levantamento foi de caráter quali-quantitativo, do tipo censo, também denominado inventário total. O formulário adotado para a análise das árvores do centro de João Pessoa contempla as seguintes informações: data da visita, nome do logradouro, número da casa mais próxima (para a localização do vegetal), espécie e seu respectivo nome popular, porte, altura da primeira ramificação e diâmetro do caule à altura do peito (DAP).

A coleta de dados foi realizada no período de dezembro de 2009 a agosto de 2010. Árvores existentes dentro de áreas particulares, como jardins residenciais, escolas e demais estabelecimentos comerciais, não foram analisadas. Também foram desconsideradas as mudas e as plantas de hábito herbáceo e arbustivo. Para a estimativa do porte foram utilizadas fotografias das árvores tendo uma pessoa como referência. A classificação foi feita de acordo com Mascaró et al. (2005): pequeno porte - árvores que atingem um máximo de seis metros; médio porte - as que alcançam entre 6 e 10 metros; e grande porte - as que ultrapassam os 10 metros de altura.

A frequência relativa de cada espécie foi calculada através da razão entre o número de indivíduos da espécie e o número total de indivíduos analisados, multiplicado por 100. A altura do peito considerada foi de 1,30m a partir do solo. Segundo a metodologia proposta por Gonçalves et al. (2004), a partir do valor do perímetro à altura do peito (PAP) obteve-se o diâmetro à altura do peito (DAP), segundo a fórmula: $\mathrm{DAP}=(\mathrm{PAP} / 3,1416)$, por meio da qual as árvores foram agrupadas nas seguintes classes: 0 a $0,5 \mathrm{~m} ; 0,5 \mathrm{~m}$ a $1,0 \mathrm{~m}$; e acima de $1,0 \mathrm{~m} . \mathrm{s}$

\section{RESULTADOS E DISCUSSÃO}

O levantamento registrou a presença de 527 indivíduos e 32 espécies, com uma média de 56,42 árvores por quilômetro de avenida. Considerando que o número ideal são 100 árvores/Km (PAIVA et al., 2010), as avenidas analisadas no centro de João Pessoa apresentam um número bem abaixo do recomendado. Este fator se torna preocupante também quando considerados os componentes do solo, constituídos principalmente de materiais impermeáveis (concreto, asfalto, pavimento), e a forte incidência de radiação solar, que contribuem de forma expressiva para o desconforto térmico e a formação de ilhas de calor na cidade (SANTOS et al., 2012).

Por outro lado, a quantidade de árvores por quilometro no centro de João Pessoa pode ser considerado um valor alto quando comparado com outras cidades brasileiras (ROSSATTO et al., 2008). Ele está acima dos encontrados em: de Rio Branco-AC (4,57 árvores/Km) (PAIVA et al., 2010), Cachoeira do SulRS (12,31 árvores/Km) (LINDENMAIER et al., 2008) e Sete de Setembro-RS (5,94 árvores/ Km) (COLETTO et 
al., 2008). Observa-se, porém, que todas as cidades mencionadas apresentaram maior diversidade de espécies quando comparada com os números do presente estudo (Tabela 1).

Tabela 1: Espécies arbóreas identificadas no centro de João Pessoa/PB, nome vulgar, família, número de indivíduos e frequência relativa (f(\%)). Classes de DAP (I - Abaixo de 0,5 m; II - Entre 0,5 m e 1,0 $\mathrm{m}$; III - Acima de 1,0 $\mathrm{m}$ ) *Espécies nativas.

\begin{tabular}{|c|c|c|c|c|}
\hline Nome científico & N. de indivíduos & $f(\%)$ & N. avenidas presentes & DAP \\
\hline \multicolumn{5}{|l|}{ Anacardiaceae } \\
\hline Mangifera indica $\mathrm{L}$. & 128 & 24,28 & 6 & $I, I I, I I I$ \\
\hline Anacardium occidentale L.* & 1 & 0,18 & 1 & II \\
\hline \multicolumn{5}{|l|}{ Arecaceae } \\
\hline Roystonea oleracea (Jacq.) O.F. Cook & 23 & 4,36 & 3 & I, II \\
\hline Cocos nucifera L. & 3 & 0,56 & 1 & 1 \\
\hline Pritchardia pacifica Seemann \& H.Wendl & 1 & 0,18 & 1 & 1 \\
\hline \multicolumn{5}{|l|}{ Bignoniaceae } \\
\hline Spathodea campanulata P. Beauv & 1 & 0,18 & 1 & III \\
\hline Tabebuia sp. & 66 & 12,52 & 3 & I, II \\
\hline Tabebuia impetiginosa (Mart. ex DC.) Standl.* & 11 & 2,08 & 1 & $\mathrm{I}$ \\
\hline Tabebuia chrysotricha (Mart. ex A. DC.) Standl.* & 8 & 1,51 & 1 & $\mathrm{I}$ \\
\hline \multicolumn{5}{|l|}{ Combretaceae } \\
\hline Terminalia catappa L. & 20 & 3,79 & 4 & I, II, III \\
\hline \multicolumn{5}{|l|}{ Cupressaceae } \\
\hline Cupressus lusitanica Mill. & 2 & 0,37 & 1 & 1,11 \\
\hline \multicolumn{5}{|l|}{ Fabaceae } \\
\hline Senna siamea (Lam.) H. S. Irwin \& Barneby & 53 & 10,05 & 5 & $I, I I, I I I$ \\
\hline Adenanthera pavonina L. & 51 & 9,67 & 7 & $I, I I, I I I$ \\
\hline Pithecellobium dulce (Roxb.) Benth. & 24 & 4,55 & 1 & $I, I I, I I I \mid$ \\
\hline Clitoria fairchildiana R. A. Howard* & 4 & 0,75 & 2 & 1,11 \\
\hline Albizzia lebbeck Benth. & 3 & 0,56 & 1 & $\mathrm{I}$ \\
\hline Schizolobium sp. & 3 & 0,56 & 1 & I, II \\
\hline Caesalpinia echinata Lam.* & 1 & 0,18 & 1 & $\mathrm{I}$ \\
\hline Delonix regia (Bojer ex Hook.) Raf. & 1 & 0,18 & 1 & II \\
\hline Cassia grandis L. f.* & 1 & 0,18 & 1 & 1 \\
\hline \multicolumn{5}{|l|}{ Malvaceae } \\
\hline Hibiscus tiliaceus L. & 1 & 0,18 & 1 & II \\
\hline \multicolumn{5}{|l|}{ Moraceae } \\
\hline Ficus benjamina $\mathrm{L}$ & 24 & 4,55 & 8 & $I, I I, I I I$ \\
\hline Ficus benjamina var. benjamina & 2 & 0,37 & 2 & I \\
\hline Indeterminada 2 (Av. Tabajaras) & 1 & 0,18 & 1 & II \\
\hline \multicolumn{5}{|l|}{ Myrtaceae } \\
\hline Psidium guajava L. * & 2 & 0,37 & 2 & 1,11 \\
\hline Syzygium jambolanum (Lam.) DC. & 2 & 0,37 & 1 & 1,11 \\
\hline Eugenia malaccensis $\mathrm{L}$. & 70 & 13,28 & 6 & 1,11 \\
\hline \multicolumn{5}{|l|}{ Pinaceae } \\
\hline Pinus sp. & 6 & 1,13 & 1 & 1 \\
\hline \multicolumn{5}{|l|}{ Sapindaceae } \\
\hline Filicium decipiens (Wight \& Arn.) Thwaites & 1 & 0,18 & 1 & $\mathrm{I}$ \\
\hline \multicolumn{5}{|l|}{ Sapotaceae } \\
\hline Achras sapota L.* & 1 & 0,18 & 1 & 1 \\
\hline Indeterminada 1 (Av. Tabajaras) & 11 & 2,08 & 1 & 1 \\
\hline Indeterminada 3 (Av. G. Osório) & 1 & 0,18 & 1 & $\mathrm{I}$ \\
\hline TOTAL & 527 & & & \\
\hline
\end{tabular}

As famílias mais abundantes foram Fabaceae (27,38\%), Anacardiaceae $(25,05 \%)$ e Bignoniaceae $(16,7 \%)$. Tais famílias também são bastante frequentes na arborização de outras cidades brasileiras (FERRAZ, 2012; PARRY et al., 2012; BONALDI et al., 2016). O predomínio de Fabaceae e Bignoniaceae confirma os resultados encontrados em outros trabalhos que verificaram a predominância de inúmeras espécies destas famílias (GÓES, 2009; BLUM et al., 2008; MATOS et al., 2010). De acordo com SOUZA et al. (2008), ambas constituem famílias amplamente distribuídas pelo país e pelo mundo, sendo utilizadas pelo seu alto potencial 
paisagístico (flores geralmente vistosas), são também comumente encontradas na Mata Atlântica. Anacardiaceae possui distribuição mais restrita (tropical e subtropical) e as flores são pouco vistosas, porém diversas espécies possuem frutos comestíveis que são mundialmente comercializados (SOUZA et al., 2008), o que pode ter favorecido a sua grande utilização na arborização de João Pessoa.

Apesar de ocorrerem em quantidades bastante reduzidas, duas espécies de Gimnospermas foram registradas (famílias Pinaceae $-1,13 \%$ e Cupressaceae - 0,37\%). Das 32 espécies registradas, houve o predomínio de 11, correspondendo a um percentual de $91 \%$ do total de indivíduos analisados. As Gimnospermas são pouco frequentes na arborização das vias públicas brasileiras (MIRANDA et al., 2009; RABER et al., 2010; PIRES et al., 2010) estando presentes principalmente nos jardins particulares. De acordo com Lorenzi et al. (2001), as principais espécies de Gimnospermas (Pinaceae e Cupressaceae) usadas no paisagismo brasileiro se adaptam melhor em temperaturas amenas, porém algumas toleram o calor, e necessitam de irrigação frequente e alta umidade do ar, o que pode ter favorecido seu cultivo em João Pessoa.

A maior quantidade de indivíduos foi observada na Avenida Camilo de Holanda e a menor foi observada na Rua Desembargador Souto Maior (Tabela 2). As avenidas com maior quantidade de espécies foram Duarte da Silveira e Pedro I (11 espécies cada) e a avenida com menor quantidade de espécies foi a Maximiano de Figueiredo, tendo apenas uma espécie ( $M$. indica) nos seus 950 metros de extensão. Foi possível observar no centro de João Pessoa o plantio desordenado, especialmente na Avenida Sanhauá, caracterizada por grande número de árvores frutíferas plantadas aleatoriamente e fora dos padrões técnicos recomendados.

Tabela 2: Extensão e largura das avenidas analisadas no centro de João Pessoa/PB, número de indivíduos, número de espécies e localização das árvores. Localização das árvores: cc-canteiro central, c-calçada, vp-via pública.

\begin{tabular}{|c|c|c|c|c|c|c|c|}
\hline \multirow[t]{2}{*}{ Nome do logradouro } & \multirow[t]{2}{*}{ Extensão (km) } & \multirow[t]{2}{*}{ Largura(m) } & \multirow[t]{2}{*}{$N^{\circ}$ de árvores } & \multirow[t]{2}{*}{ No de espécies } & \multicolumn{3}{|c|}{ Localização } \\
\hline & & & & & $\mathrm{CC}$ & c & $\mathrm{vp}$ \\
\hline Av. Almirante Barroso & 0,90 & 10,50 & 29 & 4 & 28 & 1 & - \\
\hline Av. Camilo de Holanda & 1,18 & 12,60 & 62 & 8 & 58 & 4 & - \\
\hline Av. Coremas & 1,00 & 10,50 & 45 & 5 & 2 & 4 & 39 \\
\hline R. Des. Souto Maior & 0,33 & 10,50 & 7 & 2 & 7 & 0 & - \\
\hline Av. Duarte da Silveira & 0,65 & 14 & 59 & 11 & 48 & 11 & - \\
\hline Av. dos Tabajaras & 1,15 & 12,60 & 25 & 5 & 21 & 4 & - \\
\hline Av. General Osório & 0,35 & 8,40 & 38 & 6 & 38 & 0 & - \\
\hline Av. Getúlio Vargas & 0,42 & 23,80 & 57 & 5 & 39 & 18 & - \\
\hline Av. João Machado & 1,40 & 9,80 & 59 & 2 & & & \\
\hline Av. Maximiano de Figueiredo & 0,95 & 11,20 & 36 & 1 & 36 & 0 & - \\
\hline Av. Pedro I & 0,31 & 10,50 & 53 & 11 & 52 & 1 & - \\
\hline Av. Sanhauá & 0,70 & 11,20 & 57 & 9 & 41 & 4 & - \\
\hline Total & 9,34 & & 527 & & & & \\
\hline
\end{tabular}

Com relação à frequência das espécies, observou-se o predomínio de uma ou poucas espécies em todas as avenidas do centro de João Pessoa, constatando-se uma baixa diversidade arbórea. Esta característica é comum nas cidades brasileiras (ROSSATTO et al., 2008; GÓES, 2009; PAIVA et al., 2010; MATOS et al., 2010; BARROS et al., 2010; SUCOMINE et al., 2010). A diversidade observada no centro de João Pessoa foi inferior à das cidades de Assis-SP (ROSSATTO et al., 2008), Sete de Setembro/RS (COLETTO et 
al., 2008) e Aracaju/SE (MATOS et al., 2010), caracterizando uma arborização mais homogênea do que a dessas cidades.

Observou-se que $81,4 \%$ das espécies do centro de João Pessoa são exóticas. Aspecto comum em cidades brasileiras, apesar de possuir uma flora nativa com centenas de espécies de qualidade paisagística, a maioria das plantas arbóreas cultivadas em ruas, avenidas, parques e praças das cidades brasileiras é oriunda de outros países (SILVA et al., 2007).

Almeida (2009), estudando cinco cidades no Mato Grosso, registrou os seguintes percentuais de espécies exóticas: Matupá (64\%), Alta Floresta (63\%), Nova Monte Verde (57\%), Colíder (54\%) e Carlinda (50\%). Em Salvador, Góes (2009) também registrou o predomínio de exóticas (53,3\%). Silva et al. (2008) encontraram em Franca/SP, 68,5\% dos indivíduos exóticos. Rossatto et al. (2008) registraram 61,82\% em Assis/SP. Paiva et al. (2010) em Rio Branco/AC registraram 78,57\% de exóticas. Na cidade de Sete de Setembro-RS, 58,33\% são exóticas (COLETTO et al., 2008).

As espécies exóticas encontradas em João Pessoa estão relacionadas com inúmeros problemas urbanos, relatados por outros autores. Pivetta et al. (2002) destacam alguns dos problemas mais frequentes. A castanhola (T. catappa), por exemplo, possui folhas grandes, que se desprendem das árvores, sujando as calçadas e ruas, além de causar entupimento da rede pluvial. Senna siamea é uma espécie de rápido crescimento, cuja madeira é de baixa densidade e, consequentemente, baixa resistência mecânica, quebrando com facilidade e causando transtornos devido à queda de galhos. O Flamboyant (D. regia) não é indicado para arborização de ruas, por apresentar raízes superficiais que podem danificar as calçadas (BARROS et al., 2010) e o forma de crescimento dos ramos que danifica as redes de fiação elétrica (FARIA et al., 2007). O sombreiro (C. fairchildiana) é uma espécie que apresenta ataque de insetos desfolhadores em toda a região metropolitana do Rio de Janeiro. Ficus benjamina, apesar do seu caráter paisagístico, é relacionada a inúmeros conflitos com fiação, construções, calçadas, meio-fio, iluminação e sinalização (PARRY et al., 2012; SILVA et al., 2016). Rocha et al. (2004) destacam que esta espécie, apesar de estar verde durante todo o ano e de ser propícia à topiaria, é prejudicial à estrutura viária, sendo associada a danos ao calçamento, encanamentos e conflitos com as redes aéreas.

As palmeiras imperiais em geral não são apropriadas para uso em calçadas, tanto pelo porte, que entra em conflito com a fiação, como pela dificuldade de manejo, já que não podem ser podadas (GONÇALVES et al., 2009). Uma espécie importante a observar no ambiente urbano é o coqueiro (C. nucifera), apesar da baixa abundância registrada no presente estudo, suas grandes folhas e frutos (cocos) o tornam inviável para áreas de trânsito de carros e pedestres. O plantio nestes lugares exige constante manutenção e, portanto, um alto custo energético (econômico) (GÓES, 2009).

De acordo com Gonçalves et al. (2009), a preferência dos ambientalistas pelas espécies exóticas, tanto de outras regiões do país, como estrangeiras, se deve ao desconhecimento da grande diversidade das espécies nativas e à comodidade de usar as espécies tidas como bem adaptadas em outros lugares. Por isso, determinadas espécies são utilizadas na arborização urbana em praticamente todo o país, enquanto espécies nativas promissoras são esquecidas. Em João Pessoa, a alteração desse padrão é observado nas crescentes 
pesquisas sobre suas áreas verdes, onde se registra planejamentos governamentais e sociais que visam o plantio de espécies arbóreas nativas em ambiente urbano e a proteção de demais espaços verdes (SEMAN, 2012) e o Plano Municipal de conservação da Mata Atlântica (SEMAN, 2010). Porém, de acordo com Silva (2012), apesar do planejamento, poucas ações têm sido efetivamente colocadas ação. Estudos mais recentes e diagnósticos mais precisos são necessários para se verificar a ocorrência de novos plantios, em conformidade com o Plano Diretor Municipal, e se existe o monitoramento dos novos indivíduos arbóreos.

Nas avenidas analisadas, 39\% das árvores possuíam altura superior a 10 metros, sendo, portanto, enquadradas na classificação de grande porte. Em plantas localizadas sob fiação elétrica, os portes médio e grande podem significar interferência nos fios elétricos e outros equipamentos urbanos, sendo necessário o constante acompanhamento para se verificar a necessidade de podas. As avenidas Tabajaras (90\%), Getúlio Vargas (64\%) e João Machado (55\%) foram as que apresentam os maiores percentuais de árvores de grande porte, o que implica em áreas de maior atenção a manutenção por parte dos órgãos de controle.

A maioria das cidades brasileiras apresenta predomínio de árvores de médio e grande porte, mas quando a quantidade de indivíduos de pequeno porte é maior, pode significar plantios recentes, indivíduos jovens ou espécies que naturalmente não atingem grandes alturas (ALMEIDA, 2009; COLETTO et al., 2008). O grande número de espécies de médio e grande porte no centro de João Pessoa indica árvores de idade avançada, que apesar de importantes para a amenização da temperatura, demandam cuidados com a fiação e outros equipamentos urbanos, necessitando de podas constantes. É imprescindível o acompanhamento do seu estado fitossanitário, pois se trata de indivíduos com certo risco de queda. Foi observado nessas árvores grande número de podas drásticas, realizadas pela companhia de energia elétrica. Tais podas podem proporcionar a o apodrecimento da madeira e a proliferação de cupins.

Por outro lado, a ausência de indivíduos de pequeno porte, como se observou na R. Desembargador Souto Maior, poderá afetar a estabilidade da população futuramente por não haver indivíduos jovens bem estabelecidos no meio urbano (ALMEIDA, 2009). Caracterizando, portanto, a necessidade de replantio de novos indivíduos.

Com relação à altura da primeira ramificação, onde se observa que $65 \%$ das árvores do centro de João Pessoa apresentavam seu primeiro ramo bifurcando-se a uma altura inferior a 1,80m. Esta característica é um indicativo de risco de quebra de galhos no lugar da bifurcação e pode torná-las susceptíveis a problemas com o trânsito de pedestres e veículos. O problema se agrava quando os canteiros e calçadas são muito estreitos, dificultando o uso pelos pedestres.

De acordo com Gonçalves et al. (2004), as mudas destinadas à arborização urbana devem ser preparadas através da poda de condução ainda no viveiro para atingirem a altura da primeira ramificação recomendada. É possível que esse cuidado não tenha sido seguido nos primeiros plantios da arborização de João Pessoa, em virtude do grande número de indivíduos com baixa estatura da primeira ramificação. No centro da cidade de São Carlos/SP, Sucomine et al. (2010) registraram a média da altura da primeira bifurcação em $87 \mathrm{~cm}$ e consideram este valor bem abaixo do padrão recomendado de 1,80m. Observando as mudas, estes autores registraram que 31,3\% delas possuíam um valor igual ou superior ao estipulado (três 
centímetros), o que consideram uma situação de baixa qualidade das mudas produzidas e a falta de poda de condução.

A altura mínima de inserção do primeiro galho também visa dar maior chance da muda sobreviver no meio urbano, sendo menos suscetível ao vandalismo. No caso das árvores de João Pessoa analisadas no presente estudo, não se deve considerar a competição por luz como sendo influência para a baixa estatura da primeira ramificação, uma vez que as árvores apresentaram-se isoladas umas das outras, portanto com grande disponibilidade de luz. Já com relação às podas de rebaixamento, é possível que elas possam estar contribuindo para a baixa estatura dos indivíduos, pois essas árvores sofrem constantes podas, principalmente para evitar seu contato com a fiação.

As avenidas que apresentaram árvores com as maiores alturas das primeiras ramificações foram a João Machado (52,5\%) e a Coremas (51,1\%). Merecem atenção especial as avenidas Maximiano de Figueiredo, Duarte da Silveira e Sanhauá, que apresentaram os menores percentuais deste parâmetro (25\%, $23 \%$ e $10 \%$, respectivamente). Essas avenidas possuem canteiros muito estreitos, embora as tornem mais agradáveis, são muito perigosos para a circulação dos pedestres, em virtude da baixa estatura das copas. Apesar de possuírem calçadas largas, os pedestres não podem desfrutar da sombra, pois a grande maioria das árvores encontra-se nos canteiros centrais. Barbosa et al. (2015), analisando a Av. Ulisses Guimaraes, na cidade de Terezina/PI, mostram um modelo da canteiro central onde as árvores se distribuem de variadas maneiras, ocupando a área central e as laterais, disponibilizando área livre para circulação de pedestres. Este padrão pode ser considerado no planejamento de novos espaços destinados a árvores urbanas em João Pessoa.

Observou-se que a maioria das árvores presentes no centro de João Pessoa possui o DAP inferior a 0,5m. Houve uma variação nos diâmetros de $0,05 \mathrm{~m}$ a $1,34 \mathrm{~m}$, tendo uma média de 0,48 $\pm 0,25$ metros. As avenidas Sanhauá, Tabajaras e Pedro I apresentaram as maiores quantidades de árvores com mais de 1,0m de diâmetro do caule. Este parâmetro é de grande importância no ambiente urbanizado principalmente quando associado à flexibilidade da madeira, pois troncos muito estreitos e flexíveis podem prejudicar a compatibilidade da árvore aos equipamentos urbanos, por serem mais vulneráveis à quebra ou envergamento. Por outro lado, em árvores com troncos muito largos, podem ocorrer problemas caso elas apresentem ramos muito baixos ou espinhos, podendo comprometer os espaços. No presente estudo, foram registradas oito espécies com DAP acima de 1,0m, sendo $P$. dulce $(32,22 \%)$ e $M$. indica (25\%) as duas espécies com maior quantidade de indivíduos com tal característica. Os caules da primeira apresentaram-se injuriados em sua maioria, e os cales da segunda apresentaram-se íntegros. Tal característica pode estar associada não ao diâmetro do caule, mas a outros fatores.

Uma população arbórea com DAP máximo abaixo de $80 \mathrm{~cm}$ caracteriza uma arborização formada somente por indivíduos jovens (COLETTO et al., 2008). No centro de São Carlos, Sucomine et al. (2010) registraram a média dos diâmetros à altura do peito (DAP) no valor de $21,4 \mathrm{~cm}$, considerando uma arborização formada, preponderantemente, por indivíduos jovens. Assim, pode-se dizer que a população 
arbórea analisada no centro de João Pessoa é formada principalmente por indivíduos jovens de médio porte, e em segundo lugar, por indivíduos de grande porte.

\section{CONCLUSÕES}

Conclui-se que na comunidade arbórea analisada nas vias públicas do centro de João Pessoa há uma baixa diversidade de espécies e o predomínio de espécies exóticas, assim como ocorre na maioria das cidades brasileiras. Os canteiros centrais representam espaços significativos na arborização de João Pessoa, tendo a maioria das árvores. Em todas as avenidas analisadas existe a necessidade de novos plantios, observando-se indivíduos em locais incompatíveis e longos trechos viáveis desprovidos de arborização.

Quanto à primeira ramificação é possível concluir que os atuais parâmetros recomendados para a altura mínima não foram considerados, nem na época do plantio e nem posteriormente para adequar as árvores já plantadas. Com relação ao DAP, considerando-se que as árvores urbanas estão expostas a uma grande quantidade de fatores bióticos e abióticos estressantes, estudos mais específicos são necessários para investigar qual deles está mais diretamente ligado às variações na espessura dos caules das árvores analisadas. Por enquanto, apenas se pode concluir que medidas de manejo são necessárias para aumentar a quantidade de árvores jovens para se obter uma distribuição mais homogênea das três classes de espessura do caule (pequena, média e grande). Isto irá aumentar as chances de manter o verde urbano no futuro.

Para que se amplie a quantidade de áreas verdes urbanas e se prolongue a sobrevivência das espécies arbóreas já existentes nas vias públicas de João Pessoa, é preciso que haja a implantação de um efetivo planejamento ambiental, que tenha como meta a proteção e o constante monitoramento das árvores. Esse plano deve ter como primeiro passo o inventário do seu patrimônio arbóreo, o que possibilitará o conhecimento das espécies e a sua abundância dentro da cidade.

AGRADECIMENTOS: Agradecemos ao apoio do Departamento de Engenharia e Meio Ambiente (Universidade Federal da Paraíba, Campus IV) pelas horas de trabalho concedidas para a realização deste projeto, ao Programa de Desenvolvimento e Meio Ambiente (UFPB), ao Laboratório de Ecologia Vegetal (LABEV) e ao Laboratório TAXON da UFPB, pelo auxílio nas análises.

\section{REFERÊNCIAS}

AESA. Agência Executiva de Gestão das Águas do Estado da Paraíba. Precipitação máxima dos municípios. João Pessoa: AESA, 2011.

ALMEIDA, D. N.. Análise da arborização urbana de cinco cidades da região norte do Estado de Mato Grosso. Dissertação (Mestrado em Ciências Florestais e Ambientais) - Universidade de Federal de Mato Grosso, Cuiabá, 2009.

ANDRADE, M. N. M. M.; JERONIMO, C. E. M.. Diagnóstico da arborização do espaço urbano da cidade de João Pessoa/PB. Revista Eletrônica em Gestão, Educação e Tecnologia Ambiental, Santa Maria, v.19, n.13, p.194-208, 2015.
BARBOSA, R. P.; PORTELA, M. G. T.; MACHADO, R. R. B.; SÁ, A. S.. Arborização da Avenida Deputado Ulisses Guimarães, bairro Promorar, Zona Sul de Teresina/PI. Revista da Sociedade Brasileira de Arborização Urbana, Piracicaba, v.10, n.2, p.78-89, 2015.

BARROS, E. F. S.; GUILHERME, F. A. G.; CARVALHO, R. S. Arborização urbana em quadras de diferentes padrões construtivos na cidade de Jataí. Revista Árvore, v.34, n.2, p.287-295, 2010

BLUM, C. T.; BORGO, M.; SAMPAIO, A. C. F.. Espécies exóticas invasoras na arborização de vias públicas de 
Maringá/PR. Revista da Sociedade Brasileira de Arborização Urbana, v.3, n.2, p.78-97, 2008.

BONALDI, R. A.; HASSE, I.. Flora arbórea da arborização urbana da cidade de Paranaguá, Paraná, Brasil. Revista da Sociedade Brasileira de Arborização Urbana, v.11, n.4, p.0117, 2016.

COLETTO, E. P.; MÜLLER, N. G.; WOLSKI, S. S.. Diagnóstico da arborização das vias públicas do município de Sete de Setembro/RS. Revista da Sociedade Brasileira de Arborização Urbana, v.3, n.2, p.110-122, 2008.

FARIA, J. L. G.; MONTEIRO, E. A.; FISCH, S. T. V.. Arborização de vias públicas do município de Jacareí/SP. Revista da Sociedade Brasileira de Arborização Urbana, v.2, n.4, p.2033, 2007.

FERRAZ, M. V.. Inventário das árvores urbanas da cidade de Registro/SP. Revista da Sociedade Brasileira de Arborização Urbana, v.7, n.2, p.80-88, 2012.

GÓES, G. S.. Arborização de ruas e praças em Salvador, BA à luz da Ecologia e Permacultura. Monografia (Bacharelado em Ciências Biológicas) - Universidade Federal da Bahia, Salvador, 2009.

GONÇALVES, E. O.; PAIVA, H. N.; GONÇALVES, W.; JACOVINE, L. A. G.. Avaliação qualitativa de mudas destinadas à arborização urbana no estado de Minas Gerais. Revista Árvore, v.28, n.4, p.479-486, 2004 a.

GONÇALVES, W.; PAIVA, H. N.. Árvores para o ambiente urbano. Viçosa: Aprenda Fácil, 2004b.

GONÇALVES, W.; PAIVA, H. N.; FERREIRA, D. G.; FERREIRA, R. G. S.. Arborização Urbana. Viçosa: Centro De Produções Técnicas, 2009.

IBGE. Instituto Brasileiro de Geografia e Estatística. Censo Demográfico 2010. João Pessoa: IBGE, 2017.

JOÃO PESSOA. Lei Complementar n.3: Institui o Plano Diretor da cidade de João Pessoa. João Pessoa: DOE, 1994.

JOÃO PESSOA. Constituição do Estado da Paraíba. João Pessoa: DOE, 2013.

JOÃO PESSOA. Perfil do Município de João Pessoa. João Pessoa: Prefeitura Municipal de João Pessoa, 2012.

LINDENMAIER, D. S.; SANTOS, N. O.. Arborização urbana das praças de Cachoeira do Sul, RS, BRASIL: fitogeografia, diversidade e índice de áreas verdes. Pesquisas, n.59, p.307320, 2008.

LORENZI, H.; SOUZA, H. M.. Plantas Ornamentais no Brasil: arbustivas, herbáceas e trepadeiras. 3 ed. Nova Odessa: Instituto Plantarum, 2001.

MASCARÓ, L.; MASCARÓ, J.. Vegetação Urbana. 2 ed. Porto Alegre: Mais Quatro, 2005.

MATOS, E. C. A.; NASCIMENTO-JÚNIOR, J. E.; MARIANO, D. L. S.; OLIVEIRA, A. L.. Arborização do bairro centro da cidade de Aracaju, Sergipe, e seus organismos associados. Revista da
Sociedade Brasileira de Arborização Urbana, v.5, n.4, p.2239, 2010.

MIRANDA, T. O.; CARVALHO, S. M.. Levantamento quantitativo e qualitativo de indivíduos arbóreos presentes nas vias do bairro da Ronda em Ponta Grossa/PR. Revista da Sociedade Brasileira de Arborização Urbana, v.4, n.3, p.143157, 2009.

OLIVEIRA, T. H.; PIMENTEL, R. M. M.; GALVÍNCIO, J. D. Vegetation fragment influence over urban climate. Journal of Environmental Analysis and Progress, v.2, n.1, p.72-86, 2017. DOI: http://doi.org/10.24221/jeap.2.1.2017.1116.7286

PAIVA, A. V.; LIMA, A. B. M.; CARVALHO, A.. Inventário e diagnóstico da arborização urbana viária de Rio Branco, AC. Revista da Sociedade Brasileira de Arborização Urbana, v.5, n.1, p.144-159, 2010.

PARRY, M. M.; SILVA, M. M.; SENA, I. S.; OLIVEIRA, F. P. M.. Composição florística da arborização da cidade de Altamira, Pará. Revista da Sociedade Brasileira de Arborização Urbana, v.7, n.1, p.143-158, 2012.

PIRES, N. A. M. T.; MELO, M. S.; OLIVEIRA, D. E.; XAVIERSANTOS, S.. A arborização urbana do município de Goiandira/GO: Caracterização quali-quantitativa e propostas de manejo. Revista da Sociedade Brasileira de Arborização Urbana, v.5, n.3, p.185-205, 2010.

PIVETTA, K. F. L.; SILVA FILHO, D. F.. Arborização Urbana. Jaboticabal: Boletim Acadêmico Série Arborização Urbana, 2002.

RABER, A. P.; REBELATO, G. S.. Arborização viária do município de Colorado, RS - Brasil: análise quali-quantitativa. Revista da Sociedade Brasileira de Arborização Urbana, v.5, n.1, p.183-199, 2010.

ROCHA, R. T.; LELES, P. S. S.; OLIVEIRA NETO, S. N.. Arborização de vias públicas em Nova Iguaçu, RJ: O caso dos bairros Rancho Novo e Centro. Revista Árvore, v.28, n.4, p.599-607, 2004.

ROSSATTO, D. R.; TSUBOY, M. S. F.; FREI, F.. Arborização Urbana na cidade de Assis-SP: uma abordagem quantitativa. Revista da Sociedade Brasileira de Arborização Urbana, v.3, n.3, p.1-16. 2008.

SANTOS, J. S.; SILVA, V. P. R.; SILVA, E. R.; ARAÚJO, L. E.; COSTA, A. D. L.. Campo Térmico Urbano e a sua Relação com o Uso e Cobertura do Solo em Cidade Tropical Úmida. Revista Brasileira de Geografia Física, v.3, p.540-557, 2012.

SEMAN. Secretaria Municipal de Meio Ambiente. Plano Municipal de Conservação e recuperação da Mata Atlântica. João Pessoa: Fundação SOS Mata Atlântica, 2010.

SEMAN. Secretaria Municipal de Meio Ambiente. Plano de Arborização Urbana de João Pessoa. João Pessoa: SEMAN, 2012.

SILVA, K. A. R.; LELES, P. S. S.; GIÁCOMO, R. G.; MENDONÇA, B. A. F.. Diagnóstico e uso de geoprocessamento para manejo da arborização urbana do bairro Centro da cidade do 
Rio de Janeiro/RJ. Revista da Sociedade Brasileira de Arborização Urbana, v.11, n.4, p.98-114, 2016.

SILVA, L. R.; MEUNIER, I. M. J., FREITAS, Â. M. M.. Riqueza e densidade de árvores, arvoretas e palmeiras em parques urbanos de Recife, Pernambuco, Brasil. Revista da

Sociedade Brasileira de Arborização Urbana, v.2, n.4, p.344, 2007.

SILVA, L.. Espaços verdes em João Pessoa, PB: planejamento e realidade. In: SEABRA. G.. Terra, Cidades, Natureza e Bem Estar. João Pessoa: Universitária, 2012. p.185-200.

SILVA, M. D. M.; SILVEIRA, R. P.; TEIXEIRA, M. I. J. G.. Avaliação da arborização de vias públicas de uma área da região oeste da cidade de Franca/SP. Revista da Sociedade Brasileira de Arborização Urbana, v.3, n.1, p.19-35, 2008.
SILVA, M. D.; CASTRO, A. A. B.; SILVA, B. A.; SILVA, G. J. A.; SILVEIRA, J. A. R.. Crescimento da mancha urbana na cidade de João Pessoa. In: SILVEIRA, J. A. R.; SILVA, M. D.; CASTRO, A. A. B.. Dinâmica da cidade e bordas urbanas. João Pessoa: F\&A Ltda, 2015. p.185-200.

SOUZA, V. C.; LORENZI, H.. Botânica Sistemática: guia ilustrado para identificação das famílias de Fanerógamas nativas e exóticas no Brasil, baseado em APG II. 2 ed. Nova Odessa: Instituto Plantarum, 2008.

SUCOMINE, N. M.; SALES, A.. Caracterização e análise do patrimônio arbóreo da malha viária urbana central do município de São Carlos/SP. Revista da Sociedade Brasileira de Arborização Urbana, v.5, n.4, p.128-140, 2010.

A CBPC - Companhia Brasileira de Produção Científica (CNPJ: 11.221.422/0001-03) detém os direitos materiais desta publicação. Os direitos referem-se à publicação do trabalho em qualquer parte do mundo, incluindo os direitos às renovações, expansões e disseminações da contribuição, bem como outros direitos subsidiários. Todos os trabalhos publicados eletronicamente poderão posteriormente ser publicados em coletâneas impressas sob coordenação da Sustenere Publishing, da Companhia Brasileira de Produção Científica e seus parceiros autorizados. Os (as) autores (as) preservam os direitos autorais, mas não têm permissão para a publicação da contribuição em outro meio, impresso ou digital, em português ou em tradução. 